\title{
Polymorphisms in the xenobiotic transporter Multidrug Resistance I (MDRI) and interaction with meat intake in relation to risk of colorectal cancer in a Danish prospective case-cohort study
} Vibeke Andersen*1, Mette Østergaard ${ }^{1,2}$, Jane Christensen ${ }^{3}$, Kim Overvad ${ }^{4}$, Anne Tjønneland ${ }^{3}$ and Ulla Vogel ${ }^{5,6}$

Address: ${ }^{1}$ Medical Department, Viborg Regional Hospital, DK-8800 Viborg, Denmark, ${ }^{2}$ Clinical Biochemical Department, Viborg Regional Hospital, DK-8800 Viborg, Denmark, ${ }^{3}$ Danish Cancer Society, Institute of Cancer Epidemiology, DK-2100 Copenhagen, Denmark, ${ }^{4}$ Department of Clinical Epidemiology, Aarhus University Hospital, DK-9100 Aalborg, Denmark, ${ }^{5}$ National Research Centre for the Working Environment, DK2100 Copenhagen, Denmark and ${ }^{6}$ National Food Institute, Technical University of Denmark, DK-2860 Søborg, Denmark

Email: Vibeke Andersen* - va9791@gmail.com; Mette Østergaard - mette.oestergaard@viborg.rm.dk; Jane Christensen - jane@cancer.dk; Kim Overvad - ko@dce.au.dk; Anne Tjønneland - annet@cancer.dk; Ulla Vogel - ulbvo@food.dtu.dk

* Corresponding author

Published: 21 November 2009

BMC Cancer 2009, 9:407 doi:10.1 I86/147I-2407-9-407
Received: 23 October 2008

Accepted: 21 November 2009

This article is available from: http://www.biomedcentral.com//47I-2407/9/407

(c) 2009 Andersen et al; licensee BioMed Central Ltd.

This is an Open Access article distributed under the terms of the Creative Commons Attribution License (http://creativecommons.org/licenses/by/2.0), which permits unrestricted use, distribution, and reproduction in any medium, provided the original work is properly cited.

\begin{abstract}
Background: The xenobiotic transporters, Multidrug Resistance I (MDR//ABCBI) and Breast Cancer Resistance Protein (BCRPIABCG2) may restrict intestinal absorption of various carcinogens, including heterocyclic amines $(\mathrm{HCA})$ and polycyclic aromatic hydrocarbons (PAH). Cyclooxygenase-2 (COX-2) derived prostaglandins promote gastrointestinal carcinogenesis, affecting angiogenesis, apoptosis, and invasiveness.

The aim of this study was to investigate if polymorphisms in these genes were associated with risk of colorectal cancer (CRC), and to investigate possible interactions with lifestyle factors such as smoking, meat consumption, and NSAID use.

Methods: The following polymorphisms were analyzed; a synonymous MDRI C3435T (rs 1045642) in exon26, Grs3789243-A in intron3, the functional BCRP C42IA (rs223II42), the two COX-2 A-II95G (rs689466) and G-765C (rs204I7) in the promoter region, and the COX-2 T8473C (rs5275) polymorphisms in the 3'-untranslated region. The polymorphisms were assessed together with lifestyle factors in a nested case-cohort study of 359 cases and a random cohort sample of 765 participants from the Danish prospective Diet, Cancer and Health study.
\end{abstract}

Results: Carriers of the variant allele of MDRI intron 3 polymorphism were at 1.52-fold higher risk of CRC than homozygous wild type allele carriers (Incidence rate ratio (IRR) $=1.52,95 \%$ Confidence Interval $(\mathrm{Cl})$ : I. 12-2.06). Carriers of the variant allele of MDRI C3435T exon 26 had a lower risk of CRC than homozygous C-allele carriers $(\mathrm{IRR}=0.7 \mathrm{I}$ (Cl:0.50-I.00)). There was interaction between these MDRI polymorphisms and intake of red and processed meat in relation to CRC risk. Homozygous MDRI C3435T C-allele carriers were at $8 \%$ increased risk pr 25 gram meat per day (Cl: I.00-I.16) whereas variant allele carriers were not at increased risk ( $p$ for interaction $=0.02)$. COX-2 and BCRP polymorphisms were not associated with CRC risk. There was interaction between NSAID use and MDRI C3435T and COX-2 T8473C ( $\mathrm{p}$-values for interaction $0.00 \mathrm{I}$ and 0.04 , respectively).

Conclusion: Two polymorphisms in MDRI were associated with CRC risk and there was interaction between these polymorphisms and meat intake in relation to CRC risk. Our results suggest that MDRI polymorphisms affect the relationship between meat and CRC risk. 


\section{Background}

Colorectal cancer (CRC) is one of the leading causes of cancer-related mortality in the Western World, with great impact on the life quality for the affected persons. Both genetic and life-style factors contribute to the pathogenesis, and gene-environmental interactions may modulate cancer risk. Polymorphisms in genes encoding enzymes involved in the transport and metabolism of ingested carcinogens may affect risk of CRC. In line with this, interactions between genetic polymorphisms affecting the metabolism of dietary carcinogens and meat intake have been found in relation to CRC $[1,2]$, whereas studies on the potential interactions between environmental exposure in terms of meat consumption and cigarette smoking on one side and genetic polymorphisms in genes affecting intestinal carcinogen transport on the other are scarce $[3,4]$.

The ATP-binding cassette (ABC) transporters P-glycoprotein (encoded by the Multidrug Resistance 1 (MDR1/ $A B C B 1)$ gene) and Breast Cancer Resistance Protein (BCRP, encoded by the BCRP/ABCG2 gene) are abundant in the intestine [5]. They transport a diverse spectrum of substrates from the enterocytes into the intestinal lumen, thereby restricting the exposure to these potentially harmful substances [6]. The substrates include a vast amount of structurally unrelated compounds such as various drugs [7,8]. Moreover, pesticides and insecticides [9], carcinogens such as PAHs [10] and HCAs $[6,11,12]$ and endogenous compounds such as steroids and cytokines $[13,14]$ have also been suggested as substrates. One of the most abundant dietary carcinogens formed during frying and cooking of meat, 2-Amino-1-methyl-6-phenylimidazo [4,5-b]pyridine (PhIP), is transported by BCRP [10], and probably to a lesser extent by P-glycoprotein [6]. P-glycoprotein preferentially transports large hydrophobic molecules, while BCRP is able to transport both hydrophobic and large anionic compounds, e.g. conjugates, however, the substrate specificities have been shown to be overlapping [7].

Intake of red and processed meat have been classified as risk factor for colorectal cancer (CRC) $[15,16]$. The exact mechanisms by which intake of meat and processed meat promotes carcinogenesis is, however, not clear but several different mechanisms have been proposed [17]. First, red and processed meat may be a proxy for a high fat diet or other life-style factors. Next, red and processed meat represent sources of carcinogenic heterocyclic amines (HCA), polycyclic aromatic hydrocarbons (PAH) as well as Nnitroso compounds [17] caused by cooking at high temperature and by processing of meat. Moreover, heme iron may promote carcinogenesis in combination with $\mathrm{N}$ nitroso compounds [17]. Smoking has also been reported to confer risk of CRC $[18,19]$ and tobacco contains a large number of mutagens and carcinogens, including $\mathrm{PAH}$, nitrosamines, and nicotine [20] that may reach the intestine directly via ingestion of inhaled particles which are subsequently swallowed. PAHs and other carcinogens adhered on ingested particles may dissociate from the particles and be taken up the same way as meat carcinogens.

There is increasing evidence that polymorphisms in MDR1 affect P-glycoprotein activity and expression [2123]. The synonymous MDR1 C3435T polymorphism in exon 26 has been most extensively investigated. The variant allele has been associated with lower in vitro activity and changed substrate specificity, possibly caused by a lower mRNA stability and protein folding [24,25], whereas studies on intestinal mRNA levels and protein expression levels are not consistent [22,26-28]. The potential functional effect of the MDR1 G-rs3789243A polymorphism in intron 3 is unknown [29,30]. MDR1 polymorphisms have been studied in relation to risk of CRC in previous studies, however, results are inconsistent [3,31-33].

The variant allele of the non-synonymous BCRP C421A (Q141K) polymorphism has been associated with lower protein levels and lowered transport activity both in vitro $[34,35]$ and in vivo $[27,35]$, but no associations were found between either the intestinal levels of protein and mRNA and BRCP polymorphisms [36] or between BCRP polymorphisms and risk of CRC [4].

Cyclooxygenase-2 (COX-2) plays a key role in gastrointestinal carcinogenesis, affecting angiogenesis, apoptosis, and invasiveness [37]. Moreover, COX-2 is involved in the regulation of the intestinal immune response to luminal antigens [38] and modulate the interaction between carcinogen exposure and intestinal barrier function by regulation of the intestinal immune homeostasis.

Two polymorphisms, A-1195G and G-765C in the promoter region of $C O X-2$ have been described [39]. Carriers of the variant $\mathrm{G}$-allele of -1195 lack a c-Myb binding site resulting in lowered COX-2 mRNA levels [39]. The G to C substitution at nucleotide -765 eliminates an Sp1 binding site, but meanwhile creates an E2F binding site [39]. Even though in vitro studies have revealed a lower COX-2 expression from the C-allele of G-765C allele [39], in vivo studies have shown the opposite effect $[39,40]$. A COX-2 haplotype containing the variant allele in position -765 together with the variant allele of the T8473C polymorphism in the 3' untranslated region (UTR) has been associated with high COX-2 activity [41], indicating that the 3'UTR variant allele may stabilize the mRNA level. The COX-2 A-1195G wildtype and G-765C variant alleles were associated with increased risk of CRC in a large Chinese 
study [42] in accordance with a high COX-2 level conferred by these alleles.

Long term use of aspirin and other non-steroidal antiinflammatory drugs (NSAID) has been found to confer protection against CRC $[43,44]$. The mechanism is considered to be inhibition of COX-2 activity but also COX-2 independent pathways are involved which includes antigen activation of gut inflammation [45]. Smoking has been shown to induce inflammation [46] and COX-2 expression $[47,48]$. Therefore, we hypothesized that polymorphisms affecting the intestinal barrier, i.e. intestinal transporters, and intestinal immune response may modulate the effects of smoking, meat intake and use of NSAIDs in relation to CRC risk. A priori, we expected that the variant alleles of BCRP C421A, the MDR1 C3435T, MDR1 Grs3789243-A, the COX-2 G-765C and T8473C were risk alleles, and the COX-2 A-1195G wildtype allele was the high risk allele. We searched for associations between polymorphisms in MDR1, BCRP and COX-2 and risk of CRC as well as the potential interaction with smoking, consumption of meat, and use of NSAID in a case-cohort study nested in the prospective population-based Danish Diet, Cancer and Health cohort study.

\section{Methods \\ Studied Subjects}

The subjects were selected from the Danish Diet, Cancer and Health study, an ongoing prospective cohort study [49]. Between December 1993 and May 1997, 160,725 individuals aged 50 to 64 years, born in Denmark, living in the Copenhagen and Aarhus areas and having no previous cancers at the time of invitation, were invited to participate in the study. A total of 57,053 persons accepted the invitation.

In total, 405 cases ( 184 women and 221 men) of colorectal cancer were diagnosed among the cohort members between 1994 and 2003 and registered in the files of the nationwide Danish Cancer Registry. Within the cohort we defined a sub-cohort sample including 368 women and 442 men who were randomly selected. Cases and the subcohort sample were frequency-matched on gender. Blood samples were available for 397 cases and 800 sub-cohort members. All information on genotypes and lifestyle factors was available for 372 cases and 765 sub-cohort members. 13 colorectal cancer cases diagnosed with carcinoid tumor or various other histological subtypes were excluded from the analysis, leaving 359 adenocarcinoma cases.

\section{Lifestyle variables}

At enrolment, detailed information on diet, lifestyle, weight, height, medical treatment, environmental expo- sures, and other socio-economic factors were collected [49]. In the food-frequency questionnaire, meat consumption was assessed in 12 categories of predefined responses, ranking from 'never' to 'eight times or more per day'. The daily intake was then calculated by using FoodCalc [50], this program uses population specific standardized recipes and portion sizes. Intake of red meat in grams per day was calculated by adding up intake of beef, veal, pork, lamb and offal. Intake of processed meat in grams per day was calculated by adding up intake of processed red meat, including bacon, smoked ham, salami, frankfurter, Cumberland sausage, cold cuts and liver pâté. Total dietary fibers are calculated by the AOAC methods [51]. Pearson correlation coefficients (adjusted for total energy intake) illustrating the comparison of nutient scores estimated from the food-frequency questionnaire and from the diet records were 0.39 and 0.53 for dietary fibers, 0.56 and 0.48 for iron, and 0.37 and 0.14 for meat for men and women, respectively $[52,53]$. Alcohol intake was recorded as the average frequency of intake of six types of alcoholic beverage over the preceding year: the frequency of consumption of three types of beer was recorded in bottles $(330 \mathrm{ml})$, wine in glasses $(125 \mathrm{ml})$, and fortified wine in drinks $(60 \mathrm{ml})$ and spirits in drinks $(30 \mathrm{ml})$. The predefined responses were in 12 categories, ranging from "never" to " 8 or more times a day". The alcohol content was calculated as follows: one bottle of light beer, $8.9 \mathrm{~g}$ ethanol; one bottle of regular beer, $12.2 \mathrm{~g}$ ethanol; one bottle of strong beer, $17.5 \mathrm{~g}$ ethanol; one glass of wine, $12.2 \mathrm{~g}$ ethanol; one drink of fortified wine, $9.3 \mathrm{~g}$ ethanol; and one drink of spirits, $9.9 \mathrm{~g}$ ethanol. We did not differentiate between red and white wine. Smoking intensity was calculated as gram tobacco smoked per day and included information on cigarettes (one cigarette $=1 \mathrm{~g}$ tobacco), cigars (one cigar $=4.5 \mathrm{~g}$ tobacco), cheroot (one cheroot $=4 \mathrm{~g}$ tobacco), and pipe (one pipe $=3 \mathrm{~g}$ tobacco $)$.

The lifestyle questionnaire included this question regarding use of NSAID: "Have you taken more than one pain relieving pill per month during the last year?" If the answer was yes, the participant was asked to record how frequently they took each of the following medications: "Aspirin", "Paracetamol", "Ibuprofen", or "Other pain relievers". The latter category included NSAID preparations other than aspirin and ibuprofen. Based on all records, we classified study subjects according to use of "any NSAID" ( $\geq 2$ pills per month during one year) at baseline.

Data on hormone replacement therapy (HRT), intake of dietary fibre and red meat, and anthropometric measurements was obtained as previously described [49]. The body mass index (BMI) was calculated as weight $(\mathrm{kg})$ per height $(\mathrm{m})$ squared. 


\section{Blood sampling and storage}

Blood was collected at enrolment and prepared as previously described [54]. In short, a total of $30 \mathrm{ml}$ blood was collected in citrated $(2 \times 10 \mathrm{ml})$ and plain $(1 \times 10 \mathrm{ml})$ Venojects from each non-fasting participant. Plasma, serum, lymphocytes, and erythrocytes were isolated and frozen at $-20^{\circ} \mathrm{C}$ within 2 hours. At the end of the day of collection, all samples were stored in liquid nitrogen, at $150^{\circ} \mathrm{C}$.

\section{Genotyping}

All analyses were run blinded to the case-control status. DNA was isolated from frozen lymphocytes as described by Miller et al [55]. Generally, $100 \mu \mathrm{g}$ DNA were obtained from $10^{7}$ lymphocytes. Genotyping was performed by TaqMan real-time quantitative PCR (QPCR).

MDR1 C3435T and G-rs3789243-A, BCRP C421A, and COX-2 G-765C were genotyped on an Mx3000 machine (Stratagene, La Jolla, CA, USA), using the Allelic Discrimination feature of the MxPro software (Stratagene). Reactions were carried out essentially as previously described [30], except the reaction volume was $15 \mu \mathrm{l}$. In brief, each reaction contained 1× TaqMan Universal Master Mix (Applied Biosystems, Foster City, CA, USA), approximately $20 \mathrm{ng}$ DNA, and the relevant sets of primers and locked nucleic acid (LNA)-containing probes. All reactions were run for 50 cycles with two PCR steps, denaturation and combined annealing and elongation, respectively, except for MDR1 G-rs3789243-A, where annealing and elongation were split. Verified genotype controls were included in each run. To confirm reproducibility, 20 samples for each SNP were randomly selected within each of the three genotype groups and repeated. The genotypes showed 100\% identity.

COX-2 A-1195G and T8473C were genotyped on an ABI7500 machine by endpoint readings as previously described [54]. Twenty ng of DNA were genotyped in $5 \mu \mathrm{l}$ containing 1× Mastermix (Applied Biosystems, Nærum, Denmark), $100 \mathrm{nM}$ probes, and $900 \mathrm{nM}$ primers. Controls were included in each run, and repeated genotyping of a random $10 \%$ subset yielded $100 \%$ identical genotypes.

\section{Statistical Analysis}

The analyses were performed according to the principles for the analysis of case-cohort studies as described by Barlow [56]. The analyses were performed unweighted. Age was used as the time scale in the Cox regression model. Tests and confidence intervals were based on Wald's test using the robust estimate of the variance-covariance matrix for the regression parameters in the Cox regression model [57].
All models were adjusted for baseline values of established risk factors for colorectal cancer such as BMI (kg/ $\mathrm{m}^{2}$, continuous), NSAID (yes/no), use of HRT (never/ past/current, among women), smoking status (never/ past/current), and intake of dietary fibers (g/day, continuous) and red meat (g/day, continuous).

We investigated possible interactions between the genes and selected environmental factors using the likelihood ratio test. Trend test were calculated using the Wald test. The procedure PHREG in SAS (release 9.1; SAS Institute Inc., Cary, NC, USA) was used for the statistical analyses.

\section{Ethics}

All participants gave verbal and written informed consent. Diet, Cancer and Health and the present sub-study were approved by the regional Ethics Committees on Human Studies in Copenhagen and Aarhus (Jr.nr. (KF)11-037/01 and jr.nr. (KF)01-045/93), and by the Danish Data Protection Agency.

\section{Results}

\section{Associations between genotypes and CRC risk}

Characteristics of the study population and risk factors for CRC are shown in Table 1.

The genotype distributions among the participants in the sub-cohort sample did not deviate from Hardy-Weinberg equilibrium (results not shown). Carriers of the variant allele of MDR1 G-rs3789243-A were at 1.52-fold (95\% confidence interval (CI): 1.12-2.06) higher risk of CRC than homozygous carriers of the wild type allele (Table 2). Carriers of the variant allele of MDR1 C3435T exon 26 had a lower risk of CRC than homozygous C-allele carriers $(\mathrm{IRR}=0.71$ (CI: 0.50-1.00) $) . C O X-2$ and BRCP polymorphisms were not associated with CRC risk (Table 2).

\section{Haplotype analyses}

The two MDR1 polymorphisms were in incomplete linkage such that the two variant alleles co-segregated. Homozygous carriers of the combination of the C-allele of MDR1 C3435T and the A-allele of MDR1 G-rs3789243A were at 1.80 fold higher risk of CRC (95\% CI: 1.06-3.05) than homozygous carriers of the combination of the Tallele of MDR1 C3435T and the G-allele of MDR1 Grs3789243-A. Carrier of only one of the risk alleles were generally also at higher risk of cancer, indicating that both polymorphisms contributed to the association with risk of CRC (Table 3).

Haplotype analyses combining the three polymorphisms of COX-2 revealed that four haplotypes included $97 \%$ of the observed genotype combinations in the cohort sample. COX-2 haplotypes were not associated with CRC risk (results not shown). 
Table I: Baseline characteristics of study participants selected from the Danish Diet, Cancer and Health prospective cohort study.

\begin{tabular}{|c|c|c|c|c|c|c|}
\hline & \multicolumn{2}{|c|}{ Cases } & \multicolumn{2}{|c|}{ Sub-cohort } & \multicolumn{2}{|c|}{$\operatorname{IRR}^{\mathrm{a}}(95 \% \mathrm{Cl})$} \\
\hline & No. (\%) & Median (5-95\%) & No. (\%) & Median (5-95\%) & & \\
\hline Total & $359(100)$ & & $765(100)$ & & & \\
\hline \multicolumn{7}{|l|}{ Gender } \\
\hline Men & $200(56)$ & & $419(55)$ & & & \\
\hline Women & $159(44)$ & & $346(45)$ & & & \\
\hline Age at inclusion & & $59(5 \mid-64)$ & & $56(50-64)$ & & \\
\hline \multicolumn{7}{|l|}{ Topology } \\
\hline Proximal segment of colon & $42(12)$ & & - & & & \\
\hline Distal segment of colon & $142(40)$ & & - & & & \\
\hline Rectal & $129(36)$ & & - & & & \\
\hline Not specified & $46(13)$ & & - & & & \\
\hline $\mathrm{BMI}, \mathrm{kg} / \mathrm{m}^{2}$ & & $26(21-34)$ & & $26(20-33)$ & $1.02^{b}$ & $(0.96-1.09)$ \\
\hline \multicolumn{7}{|l|}{ Food intake } \\
\hline Alcohol, g/day & & $14(1-69)$ & & $13(1-64)$ & $1.06^{b}$ & $(1.00-1.13)$ \\
\hline Red meat, g/day & & $82(36-170)$ & & $82(32-175)$ & $1.02^{b}$ & $(0.94-I .12)$ \\
\hline Processed meat, g/day & & $26(6-80)$ & & $26(4-78)$ & $1.00^{b}$ & $(0.85-1.19)$ \\
\hline Dietary fibers g/day & & $20(10-32)$ & & $21(11-34)$ & $0.62^{b}$ & $(0.37-1.02)$ \\
\hline \multicolumn{7}{|l|}{ Smoking status at inclusion } \\
\hline Never & III (3I) & & $262(34)$ & & 1.00 & - \\
\hline Former & $112(31)$ & & $239(31)$ & & 1.02 & $(0.73-1.42)$ \\
\hline Present & $136(38)$ & & $264(35)$ & & 1.15 & $(0.83-1.61)$ \\
\hline \multicolumn{7}{|l|}{ NSAID use } \\
\hline No & $244(68)$ & & $528(69)$ & & 1.00 & - \\
\hline Yes & $115(32)$ & & $237(31)$ & & 1.07 & $(0.80-1.42)$ \\
\hline \multicolumn{7}{|l|}{ HRT use among women } \\
\hline Never & $93(58)$ & & 181 (52) & & 1.00 & - \\
\hline Former & $25(16)$ & & $60(17)$ & & 0.68 & $(0.39-1.18)$ \\
\hline Present & $4 \mid(26)$ & & $105(30)$ & & 0.70 & $(0.44-1.10)$ \\
\hline
\end{tabular}

a Mutually adjusted.

b BMl pr. 2 kg/m². Alcohol pr. 10 g/day. Red meat, processed meat and dietary fibers pr $25 \mathrm{~g} /$ day.

Observed median values (5-95 percentiles) or percents of the distribution of alcohol, NSAID, smoking and potential colorectal cancer confounders among cases and members of the comparison group.

\section{Gene-gene and gene-environment analyses}

Since we observed no gene-dose effects, variant genotypes were combined in subsequent interaction analyses to maximize the statistical power. No gene-gene interaction between the MDR1 G-rs3789243-A and COX-2 T8473C polymorphisms was found (results not shown). Since we observed no allele-dose effects, variant genotypes were combined in subsequent interaction analyses to maximize the statistical power. There was interaction between the studied MDR1 polymorphisms and intake of red and processed meat in relation to CRC risk (Table 4). Variant allele carriers of MDR1 G-rs3789243-A were at 3\% higher risk pr $25 \mathrm{~g}$ meat/day (CI: 0.98-1.09) whereas for homozygous carriers of the wild type allele the association was in the opposite direction although not statistically sig- nificant (IRR pr $25 \mathrm{~g} /$ day: 0.95, CI: 0.89-1.02, p for interaction $=0.01)$. Homozygous MDR1 C3435T C-allele carriers were at $8 \%$ higher risk pr 25 g meat/day (CI: 1.001.16) whereas variant allele carriers were not at risk by meat intake (IRR pr $25 \mathrm{~g} /$ day 1.00, CI: 0.95-1.06, p for interaction $=0.02)$. No interaction was found for $B C R P$ C421A.

We found interaction between MDR1 C3435T and NSAID use in relation to risk of CRC (Table 5). Among homozygous carriers of the C-allele, NSAID use was associated with 2.34-fold (CI: 1.22-4.48) higher risk of CRC compared to non-users, whereas NSAID use had no effect among variant allele carriers ( $p$ for interaction 0.001). Likewise, there was a marginally statistically significant 
Table 2: Incidence rate ratio for colorectal cancer for the studied gene polymorphisms.

\begin{tabular}{|c|c|c|c|c|c|c|c|}
\hline & $\mathbf{N}_{\text {Case }}$ & $\mathbf{N}_{\text {Sub-cohort }}$ & IRR $^{\mathbf{a}}$ & $(95 \% \mathrm{Cl})$ & $\mathbf{I R R}^{\mathbf{b}}$ & $(95 \% \mathrm{Cl})$ & P-value \\
\hline \multicolumn{8}{|c|}{ MDRI G-rs3789243-A } \\
\hline GG & 81 & 224 & 1.00 & - & 1.00 & - & 0.03 \\
\hline GA & 194 & 365 & 1.55 & $(1.13-2.12)$ & 1.55 & $(1.12-2.14)$ & \\
\hline AA & 84 & 176 & $\mathrm{I} .43$ & $(0.98-2.08)$ & 1.45 & $(0.99-2.13)$ & \\
\hline $\mathrm{GA}$ and $\mathrm{AA}$ & 278 & 541 & 1.51 & $(1.12-2.04)$ & 1.52 & $(1.12-2.06)$ & \\
\hline \multicolumn{8}{|l|}{ MDRI C3435T } \\
\hline $\mathrm{CC}$ & 73 & 118 & 1.00 & - & 1.00 & - & 0.11 \\
\hline $\mathrm{CT}$ & 174 & 385 & 0.69 & $(0.49-0.99)$ & 0.74 & $(0.5|-| .07)$ & \\
\hline $\mathrm{TT}$ & 112 & 262 & 0.66 & $(0.45-0.96)$ & 0.66 & $(0.45-0.98)$ & \\
\hline CT and TT & 286 & 647 & 0.68 & $(0.48-0.95)$ & 0.71 & $(0.50-1.00)$ & \\
\hline \multicolumn{8}{|l|}{ COX-2 G-765C } \\
\hline GG & 267 & 566 & 1.00 & - & 1.00 & - & 0.91 \\
\hline CG & 83 & 186 & 1.02 & $(0.75-1.39)$ & 1.03 & $(0.75-I .4 I)$ & \\
\hline $\mathrm{CC}$ & 9 & 13 & 1.45 & $(0.6 \mathrm{I}-3.48)$ & 1.21 & $(0.49-2.98)$ & \\
\hline CG and CC & 92 & 199 & 1.05 & $(0.78-I .4 I)$ & 1.04 & $(0.77-1.42)$ & \\
\hline \multicolumn{8}{|l|}{ COX-2 A-II95G } \\
\hline $\mathrm{AA}$ & 230 & 482 & 1.00 & - & 1.00 & - & 0.88 \\
\hline$A G$ & 116 & 258 & 0.94 & $(0.7 \mid-I .24)$ & 0.93 & $(0.70-1.23)$ & \\
\hline GG & 13 & 25 & 0.90 & $(0.44-1.85)$ & 0.94 & $(0.45-1.95)$ & \\
\hline AG and GG & 129 & 283 & 0.93 & $(0.7 I-I .22)$ & 0.93 & $(0.7 I-I .23)$ & \\
\hline \multicolumn{8}{|l|}{ COX-2 T8473C } \\
\hline TT & 147 & 315 & 1.00 & - & 1.00 & - & 0.37 \\
\hline $\mathrm{CT}$ & 178 & 355 & 1.12 & $(0.85-1.48)$ & 1.11 & $(0.83-1.47)$ & \\
\hline $\mathrm{CC}$ & 34 & 95 & 0.82 & $(0.52-1.29)$ & 0.81 & $(0.5 I-1.28)$ & \\
\hline$C T$ and $C C$ & 212 & 450 & 1.06 & $(0.81-1.38)$ & 1.05 & $(0.80-1.37)$ & \\
\hline \multicolumn{8}{|l|}{$B R C P C 42$ IA } \\
\hline $\mathrm{CC}$ & 296 & 592 & 1.00 & - & 1.00 & - & 0.16 \\
\hline $\mathrm{CA}$ & 58 & 161 & 0.72 & $(0.5 I-I .0 I)$ & 0.71 & $(0.50-1.01)$ & \\
\hline AA & 5 & 12 & 1.10 & $(0.38-3.21)$ & 1.17 & $(0.39-3.57)$ & \\
\hline $\mathrm{CA}$ and $\mathrm{AA}$ & 63 & 173 & 0.74 & $(0.53-1.03)$ & 0.73 & $(0.52-1.04)$ & \\
\hline
\end{tabular}

aCrude (adjusted for age and sex).

bAdjusted for status of HRT (women only), smoking status, alcohol, dietary fibre, red meat, BMI and NSAID.

${ }^{c} \mathrm{p}$-value for trend for the fully adjusted estimates.

Table 3: Incidence rate ratio for colorectal cancer for combinations of MDRI genotypes

\begin{tabular}{|c|c|c|c|c|c|c|}
\hline & \multicolumn{6}{|c|}{$\operatorname{IRR}^{\mathrm{a}}(\mathbf{9 5} \% \mathrm{CI})\left(\mathbf{N}_{\text {case }} / \mathbf{N}_{\text {sub-cohort }}\right)$} \\
\hline & \multicolumn{6}{|c|}{ MDRI C3435T } \\
\hline MDRI G-rs3789243-A & CC & & CT & & TT & \\
\hline GG & 1.38 & $(0.3 \mid-6.15)$ & 1.16 & $(0.66-2.06)$ & $1.00^{\mathrm{b}}$ & - \\
\hline $\mathrm{N}_{\text {case }} / \mathrm{N}_{\text {sub-cohort }}$ & $(3 / 6)$ & & $(27 / 68)$ & & $(52 / 153)$ & \\
\hline GA & 2.20 & $(1.22-3.96)$ & 1.52 & $(1.01-2.29)$ & 1.72 & $(1.06-2.81)$ \\
\hline $\mathrm{N}_{\text {case }} / \mathrm{N}_{\text {sub-cohort }}$ & $(32 / 42)$ & & $(110 / 234)$ & & $(55 / 92)$ & \\
\hline AA & 1.80 & $(1.06-3.05)$ & 1.38 & $(0.82-2.32)$ & 1.48 & $(0.58-3.75)$ \\
\hline $\mathrm{N}_{\text {case }} / \mathrm{N}_{\text {sub-cohort }}$ & $(39 / 72)$ & & $(38 / 85)$ & & $(8 / 20)$ & \\
\hline
\end{tabular}

a Adjusted for status of HRT, smoking status, alcohol, dietary fibre, red meat and BMI.

bThe most prevalent double homozygous genotype was used as reference. 
Table 4: Interaction between intake of red and processed meat and MDRI and BCRP polymorphisms in relation to CRC risk.

\begin{tabular}{|c|c|c|c|c|c|c|c|}
\hline & $\mathbf{N}_{\text {Case }}$ & $\mathbf{N}_{\text {Sub-cohort }}$ & IRR $^{\mathbf{a}}$ & $(95 \% \mathrm{Cl})$ & $\mathbf{I R R}^{\mathbf{b}}$ & $(95 \% \mathrm{Cl})$ & P-value \\
\hline \multicolumn{8}{|c|}{ MDR/ G-rs3789243-A } \\
\hline GG & 81 & 224 & 0.95 & $(0.89-1.02)$ & 0.95 & $(0.89-1.02)$ & 0.01 \\
\hline GA and $A A$ & 278 & 541 & 1.03 & $(0.98-1.08)$ & 1.03 & $(0.98-1.09)$ & \\
\hline \multicolumn{8}{|l|}{ MDRI C3435T } \\
\hline $\mathrm{CC}$ & 73 & 118 & 1.07 & $(1.00-1.15)$ & 1.08 & $(1.00-1.16)$ & 0.02 \\
\hline $\mathrm{CT}$ and TT & 286 & 647 & 1.00 & $(0.94-1.05)$ & 1.00 & $(0.95-1.06)$ & \\
\hline \multicolumn{8}{|l|}{$B R C P C 421 \mathrm{~A}$} \\
\hline $\mathrm{CC}$ & 296 & 592 & 1.02 & $(0.97-1.07)$ & 1.02 & $(0.97-1.08)$ & 0.40 \\
\hline$C A$ and $A A$ & 63 & 173 & 0.99 & $(0.91-1.07)$ & 0.99 & $(0.91-1.08)$ & \\
\hline
\end{tabular}

IRR for colorectal cancer pr intake of additionally $25 \mathrm{~g}$ red or processed meat in relation to risk of CRC.

aCrude (adjusted for age and sex).

bAdjusted for status of HRT (women only), smoking status, alcohol, dietary fibre, BMI and NSAID.

${ }^{c} \mathrm{p}$-value for interaction between genotype and red and processed meat for the fully adjusted estimates.

interaction between COX-2 T8473C and NSAID use ( $\mathrm{p}$ for interaction 0.04). A statistically non-significantly increased risk of CRC by NSAID use was found among homozygous wild type allele carriers (IRR 1.38, CI: 0.892.14) compared to non-NSAID users, whereas NSAID use was not associated with increased CRC risk among variant allele carriers (Table 5). The same trend was seen for the COX-2 G-765C polymorphism ( $\mathrm{p}=0.06)$.

There was no interaction between the polymorphisms and smoking status in relation to CRC risk (results not shown).

Table 5: Interactions between nonsteroidal anti-inflammatory drug (NSAID) use and MDRI, COX-2 and BCRP polymorphisms.

\begin{tabular}{|c|c|c|c|c|c|c|c|c|c|c|c|}
\hline \multirow[t]{2}{*}{ Polymorphism } & \multicolumn{2}{|c|}{$\begin{array}{l}\mathbf{N}_{\text {case }} / \mathbf{N}_{\text {sub-cohort }} \\
\text { NSAID }^{\mathbf{d}}\end{array}$} & \multicolumn{4}{|c|}{$\begin{array}{l}\operatorname{lRR}^{\mathrm{a}}(95 \% \mathrm{CI}) \\
\text { NSAID }^{\mathrm{d}}\end{array}$} & \multicolumn{4}{|c|}{$\begin{array}{l}\text { IRR }^{b}(95 \% \mathrm{Cl}) \\
\text { NSAID }^{d}\end{array}$} & \multirow[t]{2}{*}{ p-value } \\
\hline & No & YES & No & & YES & & No & & YES & & \\
\hline \multicolumn{12}{|l|}{ MDRI C3435T } \\
\hline $\mathrm{CC}$ & $41 / 79$ & $32 / 39$ & 1.00 & - & 2.21 & $(1.17-4.17)$ & 1.00 & - & 2.34 & $(1.22-4.48)$ & 0.001 \\
\hline $\mathrm{CT}$ and TT & $204 / 449$ & $82 / 198$ & 0.92 & $(0.60-I .4 I)$ & 0.83 & $(0.52-1.33)$ & 0.99 & $(0.63-1.54)$ & 0.86 & $(0.53-1.39)$ & \\
\hline \multicolumn{12}{|c|}{ MDRI G-rs 3789243-A } \\
\hline GG & $54 / 160$ & $27 / 64$ & 1.00 & - & 1.35 & $(0.77-2.35)$ & 1.00 & - & 1.31 & $(0.74-2.32)$ & 0.26 \\
\hline GA and $A A$ & $191 / 368$ & $87 / 173$ & 1.65 & $(1.15-2.38)$ & 1.65 & $(1.09-2.49)$ & 1.66 & $(I .15-2.4 I)$ & 1.61 & $(1.06-2.46)$ & \\
\hline \multicolumn{12}{|l|}{ COX-2 G-765C } \\
\hline GG & $180 / 397$ & $87 / 169$ & 1.00 & - & 1.22 & $(0.89-1.69)$ & 1.00 & - & 1.20 & $(0.86-1.67)$ & 0.06 \\
\hline$C G$ and $C C$ & $65 / 131$ & $27 / 68$ & 1.22 & $(0.86-1.75)$ & 0.93 & $(0.57-1.5 I)$ & 1.23 & $(0.85-1.78)$ & 0.90 & $(0.54-1.48)$ & \\
\hline \multicolumn{12}{|l|}{ COX-2 A-1I95G } \\
\hline AA & $156 / 329$ & $74 / 153$ & 1.00 & - & 1.05 & $(0.75-\mathrm{I} .48)$ & 1.00 & - & 0.99 & $(0.69-I .4 I)$ & 0.46 \\
\hline$A G$ and $G G$ & $89 / 199$ & $40 / 84$ & 0.91 & $(0.66-1.27)$ & 1.04 & $(0.67-1.60)$ & 0.88 & $(0.63-1.23)$ & 1.04 & $(0.67-1.61)$ & \\
\hline \multicolumn{12}{|l|}{ COX-2 T8473C } \\
\hline TT & $94 / 222$ & $53 / 93$ & 1.00 & - & 1.42 & $(0.92-2.18)$ & 1.00 & - & 1.38 & $(0.89-2.14)$ & 0.04 \\
\hline$C T$ and $C C$ & $15 \mid / 306$ & $61 / 144$ & 1.23 & $(0.89-1.70)$ & 1.09 & $(0.73-1.62)$ & 1.22 & $(0.87-1.69)$ & 1.05 & $(0.70-1.58)$ & \\
\hline \multicolumn{12}{|l|}{$B C R P C 42$ IA } \\
\hline $\mathrm{CC}$ & $199 / 4 \mid 4$ & $97 / 178$ & 1.00 & - & 1.20 & $(0.88-1.63)$ & 1.00 & - & 1.18 & $(0.85-1.62)$ & 0.09 \\
\hline$C A$ and $A A$ & $46 / 114$ & $17 / 59$ & 0.86 & $(0.58-I .27)$ & 0.62 & $(0.35-I .10)$ & 0.86 & $(0.57-1.29)$ & 0.60 & $(0.33-1.08)$ & \\
\hline
\end{tabular}

aCrude (adjusted for age and sex).

bAdjusted for status of HRT (women only), smoking status, alcohol, dietary fibre, red meat and BMI.

c $\mathrm{p}$-value for interaction for the fully adjusted risk estimates.

dStudy subjects were classified according to use of "any NSAID" ( 22 pills per month during one year) at baseline 


\section{Discussion}

In the present study, both of the studied MDR1 polymorphisms were associated with CRC risk and interacted with meat intake in relation to CRC risk. Carriers of the MDR1 G-rs3789243-A A-allele and homozygous carriers of MDR1 C3435T C-allele were at higher risk of CRC than carriers of the common allele genotypes. Carriers of these two genotypes were, moreover, at higher risk of CRC in relation to intake of red and processed meat whereas carriers of the respective common allele genotypes were not at higher risk of $\mathrm{CRC}$ in relation to meat intake. COX-2 and $B C R P$ gene polymorphisms were not associated with CRC risk. Furthermore, there was interaction between NSAID use and the MDR1 C3435T and COX-2 T8473C polymorphisms in relation to risk of CRC. No gene-smoking interactions were found.

The present study design has pros and cons. Prospective studies have the advantage in relation to examining geneenvironmental interactions that they are not encumbered by recall bias. In the present study, cases and cohort sample were selected from the same cohort, which together with complete follow up of the participants, minimised the risk of selection bias. Information on lifestyle factors were collected at enrolment for all participants which minimised the risk of differential misclassification of cases and comparison group. However, lifestyle factors were only collected once, and may thus not be representative for the lifestyle during follow-up. This is, however, not expected to result in differential misclassification. Furthermore, information on food intake was based on a semi-quantitatively food frequency questionnaire $[49,53]$, which was, however, evaluated and found useable [52].

Known life-style factors affecting the risk of CRC include diet, physical activity, body mass index (BMI), alcohol, smoking and NSAID use [15]. In this study the results were adjusted for relevant confounding factors. Physical activity (habitual exercise) has been shown not to be a risk factor in this population and hence, was not adjusted for [58].

Heterozygous and homozygous variant genotype carriers were combined for the analyses of interactions due to power-considerations. Therefore, in the light of the obtained P-values and the number of statistical testes performed, we cannot exclude that our positive findings are due to chance. On the other hand, the fact that we found interaction between both of the studied MDR1 polymorphisms and meat intake in relation to CRC risk makes a chance finding less likely.

In contrast to the finding in the present study, MDR1 polymorphisms have not been associated with overall risk of
CRC in previous studies [31-33]. The only other larger study, a case-cohort study in a Norwegian population of the polymorphism G-rs3789243A [29,30] found no association between this SNP and the development of intestinal adenomas and carcinomas [3]. Smaller studies, including up to 285 cases, have not found associations with overall CRC risk among Caucasians or Koreans [3133], although an association was found between the MDR1 C3435T variant allele and CRC risk among patients diagnosed before the age of 50 years [31]. Moreover, we found no interaction between the MDR1 polymorphism and smoking status which is in contrast to a previous study showing an association between MDR1 C3435T variant allele and CRC risk among life-long nonsmokers of more than 63 years of age [33]. Relative to our study, the mentioned studies have a weaker design.

We found a relative risk by meat intake of 1.03 (95\% CI: 0.98-1.09, p for interaction $=0.01)$ and 1.08 (95\% CI: 1.00-1.16, p for interaction 0.02) per $25 \mathrm{~g}$ red and processed meat per day for the two identified risk MDR1 genotypes. The risk is in line with a previous finding of a relative risk of 1.29 per 100 g per day [16]. Moreover, meat intake was not associated with CRC risk for carriers of the other genotypes. The found interactions between MDR1 polymorphisms and intake of meat in the present study suggest that the MDR1 polymorphisms may be of minor importance in study populations with a low intake of red and processed meat.

We observed an interaction between MDR1 C3435T and NSAID use such that NSAID use was associated with increased CRC risk among homozygous carriers of the wild type allele only. In cell lines, COX-2 has been shown to induce P-glycoprotein [59] whereas COX-2 inhibition prevented the expression and function of P-glycoprotein [60], thereby affecting apoptosis [61]. A similar relationship has been found in vivo [62]. Thus, NSAID use seems to affect P-glycoprotein tumorigenesis in an incompletely understood manner. While MDR1 seems to play a role in CRC carcinogenesis, much is to be learned about the function of P-glycoprotein in relation to carcinogenesis.

The silent MDR1 C3435T polymorphism has been suggested to lead to a more unstable mRNA and consequently, lower overall activity of the variant allele should be expected [24]. Therefore, we expected that red and processed meat would be most carcinogenic among $\mathrm{T}$ allele carriers of MDR1 C3435T, whereas the opposite was found. However, in a very recent review, Fung et al suggest that the silent $\mathrm{C} 3435$ polymorphism induces a conformational change in P-glycoprotein due to ribosome stalling during translation, whereas no effect on mRNA stability was detected [25]. The two polymorphic P-glycoproteins were shown to differ in their substrate specificity, since 
transport of varapamil but not rapamycin was changed by the polymorphism [25]. Our study suggestthat red and processed meat were most carcinogenic among $\mathrm{C}$-allele carriers of MDR1 C3435T. The very large MDR1 gene includes 28 exons and is highly polymorphic which makes it difficult to identify causal polymorphisms. In addition, linkage patterns and allele frequencies in MDR1 are highly variable between different ethnic groups and thus between the studied populations [22]. Hence, casecontrol studies with assessment of multiple polymorphisms, enabling comprehensive haplotype analysis, in parallel with P-glycoprotein activity, mRNA and protein level measurements, will be required to understand MDR1 genotype-phenotype causality.

We found no association between BCRP genotypes and risk of CRC and on interaction between BCRP genotypes and meat, smoking or NSAID. Our result is in accordance with a recent gene-wide association study [4]. Our study suggests that P-glycoprotein, but not BCRP, transport certain carcinogens, which are relevant in relation to meat intake. Therefore, elucidating substrate differences between P-glycoprotein and BCRP may help to identify possible mechanisms behind meat-related carcinogenesis [63].

We found no association between COX-2 genotypes and risk of CRC. The haplotype pattern was similar to what has previously been found for Danes [54]. In accordance with our results, no association between $C O X-2$ polymorphisms and CRC was demonstrated in a large French case control study [64] and smaller studies [65,66]. Variant allele carriers of COX-2 G-765C have been reported to be at higher CRC risk among Han Chinese [42]. Other studies suggest that the effects of polymorphisms on COX-2 expression levels are large enough to have biological impact provided that COX-2 expression is important in CRC [54]. On this basis, our results suggest that COX-2 plays a limited role in colon carcinogenesis in the present study population.

Interaction between NSAID and COX-2 polymorphisms in relation to risk of CRC and colorectal adenomas has been investigated previously $[65,67,68]$. Although some studies on colorectal adenomas may suggest that the largest risk-reducing effect by NSAID use is observed among the genotypes related to high COX-2 levels, results are not consistent [68-70]. We observed interaction between COX-2 T8473C and NSAID use. NSAID use was associated with CRC risk among homozygous carriers of the COX-2 T8473C genotype, which is assumed to be associated with low expression levels. In accordance with our result, $[45,61]$ aspirin has been shown to induce COX-2 transcription in some tissues, among others intestinal myofibroblasts, especially in the presence of IL-1 $\beta$ [71]. On the other hand, induction of $C O X-2$ gene expression by inhibition of COX-2 have been demonstrated in both liver and colon cancer cell lines [45,61]. This seem to be mediated by a COX-2 independent mechanism [45], These in vitro results indicate that the tissue specific effects of NSAIDs are far from clear. Thus, the observed interaction may be a chance finding. In the 'Diet, Cancer and Health cohort, used in the present study, long term use of NSAID was associated with a protective effect against CRC [72]. However, using a higher intake of NSAID as cut-off value (weekly use) did not change our results regarding NSAID use (results not shown).

\section{Conclusion}

In conclusion, the present study indicated that the two studied MDR1 polymorphisms are associated with risk of CRC and interact with intake of red and processed meat in relation to CRC risk, whereas no association was found between BCRP and COX-2 polymorphisms and risk of CRC. Our study suggests that genetic variations in MDR1, but not BCRP, affects the intestinal absorption of meat related dietary carcinogens and that elucidating substrate differences between P-glycoprotein and BCRP may identify possible mechanisms behind meat-related carcinogenesis. This is the first study finding interactions between polymorphisms affecting intestinal transport proteins and meat intake in relation to CRC.

Next, our results suggest an increased risk of CRC by NSAID intake by homozygote MDR1 C3435T wildtype carriers. If confirmed, the present results stresses the importance of identification of possible subgroups which may not take advantage of, or may even be at increased risk, by NSAID prevention. No consistent associations were observed for $C O X-2$ polymorphisms.

\section{Abbreviations}

BCRP: Breast Cancer Resistance Protein; BMI: body mass index; CI: confidence interval; $C O X-2$ : Cyclooxygenase-2; CRC: Colorectal Cancer; HRT: hormone replacement therapy; MDR1: Multidrug Resistance 1; IRR: incidence rate ratio; NSAID: non-steroidal anti-inflammatory drug; QPCR: real-time quantitative PCR; SNP: single nucleotide polymorphism.

\section{Competing interests}

The authors declare that they have no competing interests.

\section{Authors' contributions}

$M \varnothing$ and UV carried out the molecular genetic studies. UV, $\mathrm{KO}$, AT participated in the design of the study and JC performed the statistical analysis. VA conceived the study, and participated in its design and coordination and VA, UV and JC drafted the manuscript. All authors read and approved the final manuscript. 


\section{Acknowledgements}

We thank Anne-Karin Jensen, Lourdes Pedersen, Katja Boll, and Helle G. Binderup for excellent technical support. We also thank the staff at the Library, Viborg Regional Hospital. This work was supported by "Familien Erichsens Mindefond", The Lundbeck Foundation, "Johs M Klein og Hustrus mindelegat", "Agnete Løvgreens Legat", the Danish Cancer Society, grant DP00027, the grant ENGAGE from the Novo Nordisk Foundation and a grant from the Danish Ministry of Health, Research Centre for Environmental Health's Fund, ENGAGE.

\section{References}

I. Cotterchio M, Boucher BA, Manno M, Gallinger S, Okey AB, Harper PA: Red meat intake, doneness, polymorphisms in genes that encode carcinogen-metabolizing enzymes, and colorectal cancer risk. Cancer Epidemiol Biomarkers Prev 2008, I 7:3098-3 I07.

2. Sorensen M, Autrup $H$, Olsen A, Tjonneland A, Overvad $K$, Raaschou-Nielsen O: Prospective study of NATI and NAT2 polymorphisms, tobacco smoking and meat consumption and risk of colorectal cancer. Cancer Lett 2008, 266: I86-193.

3. Andersen V, Agerstjerne L, Jensen D, Ostergaard M, Saebo M, Hamfjord J, et al.: The multidrug resistance I (MDRI) gene polymorphism G-rs3789243-A is not associated with disease susceptibility in Norwegian patients with colorectal adenoma and colorectal cancer; a case control study. BMC Med Genet 2009, 10:18.

4. Campa D, Pardini B, Naccarati A, Vodickova L, Novotny J, Forsti A, et al: A gene-wide investigation on polymorphisms in the ABCG2/BRCP transporter and susceptibility to colorectal cancer. Mutat Res 2008, 645:56-60.

5. Albermann N, Schmitz-Winnenthal FH, Z'graggen K, Volk C, Hoffmann MM, Haefeli WE, et al:: Expression of the drug transporters MDRI/ABCBI, MRPI/ABCCI, MRP2/ABCC2, BCRP/ $A B C G 2$, and $P X R$ in peripheral blood mononuclear cells and their relationship with the expression in intestine and liver. Biochem Pharmacol 2005, 70:949-958.

6. Leslie EM, Deeley RG, Cole SP: Multidrug resistance proteins: role of P-glycoprotein, MRPI, MRP2, and BCRP (ABCG2) in tissue defense. Toxicol Appl Pharmacol 2005, 204:216-237.

7. Sarkadi B, Homolya L, Szakacs G, Varadi A: Human multidrug resistance $A B C B$ and $A B C G$ transporters: participation in a chemoimmunity defense system. Physiol Rev 2006, 86: I I79-1236.

8. Ambudkar SV, Dey S, Hrycyna CA, Ramachandra M, Pastan I, Gottesman MM: Biochemical, cellular, and pharmacological aspects of the multidrug transporter. Annu Rev Pharmacol Toxicol I999, 39:36I-398

9. bu-Qare AW, Elmasry E, bou-Donia MB: A role for P-glycoprotein in environmental toxicology. J Toxicol Environ Health $B$ Crit Rev 2003, 6:279-288.

10. Ebert B, Seidel A, Lampen A: Identification of BCRP as transporter of benzo[a]pyrene conjugates metabolically formed in Caco-2 cells and its induction by Ah-receptor agonists. Carcinogenesis 2005, 26: I 754-1763.

II. Enokizono J, Kusuhara H, Ose A, Schinkel AH, Sugiyama Y: Quantitative investigation of the role of breast cancer resistance protein (Bcrp/Abcg2) in limiting brain and testis penetration of xenobiotic compounds. Drug Metab Dispos 2008, 36:995-1002.

12. van Herwaarden AE, Wagenaar E, Karnekamp B, Merino G, Jonker JW, Schinkel AH: Breast cancer resistance protein (Bcrpl/ Abcg2) reduces systemic exposure of the dietary carcinogens aflatoxin $B I, I Q$ and Trp-P-I but also mediates their secretion into breast milk. Carcinogenesis 2006, 27:I23-130.

13. Mizutani T, Masuda M, Nakai E, Furumiya K, Togawa $H$, Nakamura $Y$, et al.: Genuine functions of P-glycoprotein (ABCBI). Curr Drug Metab 2008, 9: 167-I74.

14. Johnstone RW, Ruefli AA, Smyth MJ: Multiple physiological functions for multidrug transporter P-glycoprotein? Trends Biochem Sci 2000, 25: I-6.

15. Huxley RR, Ansary-Moghaddam A, Clifton P, Czernichow S, Parr CL, Woodward $M$ : The impact of dietary and lifestyle risk factors on risk of colorectal cancer: a quantitative overview of the epidemiological evidence. Int J Cancer 2009, I 25: I7I-I80.

16. World Cancer Research Fund/American Institute for CancerResearch [http://www.dietandcancerreport.org/]
17. Santarelli RL, Pierre F, Corpet DE: Processed meat and colorectal cancer: a review of epidemiologic and experimental evidence. Nutr Cancer 2008, 60:131-144.

18. Liang PS, Chen TY, Giovannucci E: Cigarette smoking and colorectal cancer incidence and mortality: systematic review and meta-analysis. Int J Cancer 2009, I 24:2406-24I5.

19. Tsoi KK, Pau CY, Wu WK, Chan FK, Griffiths S, Sung J): Cigarette smoking and the risk of colorectal cancer: a meta-analysis of prospective cohort studies. Clin Gastroenterol Hepatol 2009, 7:682-688.

20. Seitz M, Wirthmuller U, Moller B, Villiger PM: The -308 tumour necrosis factor-alpha gene polymorphism predicts therapeutic response to TNFalpha-blockers in rheumatoid arthritis and spondyloarthritis patients. Rheumatology (Oxford) 2007, 46:93-96.

2I. leiri I, Takane H, Otsubo K: The MDR I (ABCB I) gene polymorphism and its clinical implications. Clin Pharmacokinet 2004, 43:553-576.

22. Woodahl EL, Ho RJ: The role of MDRI genetic polymorphisms in interindividual variability in $\mathbf{P}$-glycoprotein expression and function. Curr Drug Metab 2004, 5: I I-19.

23. Kroetz DL, Pauli-Magnus C, Hodges LM, Huang CC, Kawamoto M, Johns S], et al.: Sequence diversity and haplotype structure in the human ABCBI (MDRI, multidrug resistance transporter) gene. Pharmacogenetics 2003, 13:481-494.

24. Wang D, Johnson AD, Papp AC, Kroetz DL, Sadee W: Multidrug resistance polypeptide I (MDRI, ABCBI) variant 3435C>T affects mRNA stability. Pharmacogenet Genomics 2005, I 5:693-704.

25. Fung $\mathrm{KL}$, Gottesman MM: A synonymous polymorphism in a common MDR I (ABCBI) haplotype shapes protein function. Biochim Biophys Acta 2009, I 794:860-87I.

26. Larsen UL, Hyldahl OL, Guldborg NC, Eriksen J, Jakobsen P, Ostergaard $M$, et al.: Human intestinal P-glycoprotein activity estimated by the model substrate digoxin. Scand J Clin Lab Invest 2007, 67:123-134.

27. Maeda K, Sugiyama Y: Impact of genetic polymorphisms of transporters on the pharmacokinetic, pharmacodynamic and toxicological properties of anionic drugs. Drug Metab Pharmacokinet 2008, 23:223-235.

28. Hoffmeyer S, Burk O, von RO, Arnold HP, Brockmoller J, Johne A, et al: Functional polymorphisms of the human multidrugresistance gene: multiple sequence variations and correlation of one allele with P-glycoprotein expression and activity in vivo. Proc Natl Acad Sci USA 2000, 97:3473-3478.

29. Ho GT, Soranzo N, Nimmo ER, Tenesa A, Goldstein DB, Satsangi J: ABCBI/MDRI gene determines susceptibility and phenotype in ulcerative colitis: discrimination of critical variants using a gene-wide haplotype tagging approach. Hum Mol Genet 2006, I 5:797-805.

30. Ostergaard M, Ernst A, Labouriau R, Dagiliene E, Krarup HB, Christensen $M$, et al.: Cyclooxygenase-2, multidrug resistance $I$, and breast cancer resistance protein gene polymorphisms and inflammatory bowel disease in the Danish population. Scand J Gastroenterol 2009, 44:65-73.

31. Kurzawski M, Drozdzik M, Suchy J, Kurzawski G, Bialecka M, Gornik $\mathrm{W}$, et al: Polymorphism in the P-glycoprotein drug transporter MDR I gene in colon cancer patients. Eur J Clin Pharmacol 2005, 61 :389-394.

32. Bae SY, Choi SK, Kim KR, Park CS, Lee SK, Roh HK, et al.: Effects of genetic polymorphisms of MDRI, FMO3 and CYPIA2 on susceptibility to colorectal cancer in Koreans. Cancer Sci 2006, 97:774-779.

33. Osswald E, Johne A, Laschinski G, rjomand-Nahad F, Malzahn U, Kirchheiner J, et al.: Association of MDRI genotypes with susceptibility to colorectal cancer in older non-smokers. Eur J Clin Pharmacol 2007, 63:9-16.

34. Imai Y, Nakane M, Kage K, Tsukahara S, Ishikawa E, Tsuruo T, et al.: C42 I A polymorphism in the human breast cancer resistance protein gene is associated with low expression of $\mathrm{Q} / 4 \mathrm{I} \mathrm{K}$ protein and low-level drug resistance. Mol Cancer Ther 2002, I:6| | -616.

35. Urquhart BL, Ware JA, Tirona RG, Ho RH, Leake BF, Schwarz UI, et al.: Breast cancer resistance protein (ABCG2) and drug disposition: intestinal expression, polymorphisms and sulfasala- 
zine as an in vivo probe. Pharmacogenet Genomics 2008, 18:439-448.

36. Zamber CP, Lamba JK, Yasuda K, Farnum J, Thummel K, Schuetz JD, et al.: Natural allelic variants of breast cancer resistance protein (BCRP) and their relationship to BCRP expression in human intestine. Pharmacogenetics 2003, 13:19-28.

37. Chan AT, Ogino S, Fuchs CS: Aspirin and the risk of colorectal cancer in relation to the expression of COX-2. N Engl J Med 2007, 356:2/3|-2|42

38. Fukata M, Chen A, Klepper A, Krishnareddy S, Vamadevan AS, Thomas LS, et al.: Cox-2 is regulated by Toll-like receptor-4 (TLR4) signaling: Role in proliferation and apoptosis in the intestine. Gastroenterology 2006, I 3 I:862-877.

39. Zhang X, Miao X, Tan W, Ning B, Liu Z, Hong Y, et al:: Identification of functional genetic variants in cyclooxygenase-2 and their association with risk of esophageal cancer. Gastroenterology 2005, I 29:565-576.

40. Szczeklik W, Sanak M, Szczeklik A: Functional effects and gender association of COX-2 gene polymorphism G-765C in bronchial asthma. J Allergy Clin Immunol 2004, I I 4:248-253.

41. Sanak M, Szczeklik W, Szczeklik A: Association of COX-2 gene haplotypes with prostaglandins production in bronchial asthma. I Allergy Clin Immunol 2005, I 16:22I-223.

42. Tan W, Wu J, Zhang X, Guo Y, Liu J, Sun T, et al:: Associations of functional polymorphisms in cyclooxygenase- 2 and platelet I 2-lipoxygenase with risk of occurrence and advanced disease status of colorectal cancer. Carcinogenesis 2007, 28: I| $197-1201$.

43. Flossmann E, Rothwell PM: Effect of aspirin on long-term risk of colorectal cancer: consistent evidence from randomised and observational studies. Lancet 2007, 369:1603-1613.

44. Friis S, Poulsen AH, Sorensen HT, Tjonneland A, Overvad K, Vogel U, et al.: Aspirin and other non-steroidal anti-inflammatory drugs and risk of colorectal cancer: a Danish cohort study. Cancer Causes Control 2009, 20:731-740.

45. Paik JH, Ju JH, Lee JY, Boudreau MD, Hwang DH: Two opposing effects of non-steroidal anti-inflammatory drugs on the expression of the inducible cyclooxygenase. Mediation through different signaling pathways. J Biol Chem 2000, 275:28I73-28I79.

46. Hermann M, Krum H, Ruschitzka F: To the heart of the matter: coxibs, smoking, and cardiovascular risk. Circulation 2005, I I 2:94I-945.

47. Moraitis D, Du B, De Lorenzo MS, Boyle JO, Weksler BB, Cohen EG, et al: Levels of cyclooxygenase- 2 are increased in the oral mucosa of smokers: evidence for the role of epidermal growth factor receptor and its ligands. Cancer Res 2005, 65:664-670.

48. Badawi AF, Habib SL, Mohammed MA, Abadi AA, Michael MS: Influence of cigarette smoking on prostaglandin synthesis and cyclooxygenase-2 gene expression in human urinary bladder cancer. Cancer Invest 2002, 20:65I-656.

49. Tjonneland A, Olsen A, Boll K, Stripp C, Christensen J, Engholm G, et al.: Study design, exposure variables, and socioeconomic determinants of participation in Diet, Cancer and Health: a population-based prospective cohort study of 57,053 men and women in Denmark. Scand J Public Health 2007, 35:432-44I.

50. Foodcalc I.3 Computer program 1998 [http://www.ibt.ku.dk/ jesper/foodcalc/].

5I. Prosky L, Asp NG, Furda I, DeVries JW, Schweizer TF, Harland BF: Determination of total dietary fiber in foods and food products: collaborative study. J Assoc Off Anal Chem 1985, 68:677-679.

52. Tjonneland A, Overvad K, Haraldsdottir J, Bang S, Ewertz M, Jensen $O M$ : Validation of a semiquantitative food frequency questionnaire developed in Denmark. Int J Epidemiol |99|, 20:906-912.

53. Tjonneland A, Haraldsdottir J, Overvad K, Stripp C, Ewertz M, Jensen $O M$ : Influence of individually estimated portion size data on the validity of a semiquantitative food frequency questionnaire. Int J Epidemiol 1992, 21:770-777.

54. Vogel U, Christensen J, Dybdahl M, Friis S, Hansen RD, Wallin H, et al. Prospective study of interaction between alcohol, NSAID use and polymorphisms in genes involved in the inflammatory response in relation to risk of colorectal cancer. Mutat Res 2007, 624:88-100.
55. Miller SA, Dykes DD, Polesky HF: A simple salting out procedure for extracting DNA from human nucleated cells. Nucleic Acids Res 1988, 16:1215.

56. Barlow WE, Ichikawa L, Rosner D, Izumi S: Analysis of case-cohort designs. J Clin Epidemiol 1999, 52: I I65- I I72.

57. Barlow WE: Robust variance estimation for the case-cohort design. Biometrics 1994, 50:1064-1072.

58. Johnsen NF, Christensen J, Thomsen BL, Olsen A, Loft S, Overvad K, et al.: Physical activity and risk of colon cancer in a cohort of Danish middle-aged men and women. Eur J Epidemiol 2006, $21: 877-884$

59. Ziemann C, Schafer D, Rudell G, Kahl GF, Hirsch-Ernst KI: The cyclooxygenase system participates in functional mdrlb overexpression in primary rat hepatocyte cultures. Hepatology 2002, 35:579-588.

60. Zatelli MC, Luchin A, Piccin D, Tagliati F, Bottoni A, Vignali C, et al:: Cyclooxygenase-2 inhibitors reverse chemoresistance phenotype in medullary thyroid carcinoma by a permeability glycoprotein-mediated mechanism. J Clin Endocrinol Metab 2005, 90:5754-5760.

61. Fantappie O, Solazzo M, Lasagna N, Platini F, Tessitore L, Mazzanti R: P-glycoprotein mediates celecoxib-induced apoptosis in multiple drug-resistant cell lines. Cancer Res 2007, 67:4915-4923.

62. Patel VA, Dunn MJ, Sorokin A: Regulation of MDR-I (P-glycoprotein) by cyclooxygenase-2. J Biol Chem 2002, 277:389|5-38920.

63. Dietrich CG, Geier A, Oude Elferink RP: ABC of oral bioavailability: transporters as gatekeepers in the gut. Gut 2003 , 52:1788-1795.

64. Kury S, Buecher B, Robiou-du-Pont S, Scoul C, Colman H, Le NT, et al: Low-penetrance alleles predisposing to sporadic colorectal cancers: a French case-controlled genetic association study. BMC Cancer 2008, 8:326.

65. Sansbury LB, Millikan RC, Schroeder JC, North KE, Moorman PG Keku TO, et al:: COX-2 polymorphism, use of nonsteroidal anti-inflammatory drugs, and risk of colon cancer in African Americans (United States). Cancer Causes Control 2006, I7:257-266

66. Goodman JE, Bowman ED, Chanock SJ, Alberg AJ, Harris CC: Arachidonate lipoxygenase (ALOX) and cyclooxygenase (COX) polymorphisms and colon cancer risk. Carcinogenesis 2004, 25:2467-2472.

67. Cox DG, Pontes C, Guino E, Navarro M, Osorio A, Canzian F, et al.: Polymorphisms in prostaglandin synthase 2/cyclooxygenase 2 (PTGS2/COX2) and risk of colorectal cancer. $\mathrm{Br} /$ Cancer 2004, $91: 339-343$.

68. Ulrich CM, Whitton J, Yu JH, Sibert J, Sparks R, Potter JD, et al: PTGS2 (COX-2) -765G > C promoter variant reduces risk of colorectal adenoma among nonusers of nonsteroidal antiinflammatory drugs. Cancer Epidemiol Biomarkers Prev 2005, 14:616-619.

69. Gong Z, Bostick RM, Xie D, Hurley TG, Deng Z, Dixon DA, et al: Genetic polymorphisms in the cyclooxygenase-I and cyclooxygenase- 2 genes and risk of colorectal adenoma. Int J Colorectal Dis 2009, 24:647-654.

70. Barry EL, Sansbury LB, Grau MV, Ali IU, Tsang S, Munroe DJ, et al: Cyclooxygenase-2 Polymorphisms, Aspirin Treatment, and Risk for Colorectal Adenoma Recurrence--Data from a Randomized Clinical Trial. Cancer Epidemiol Biomarkers Prev 2009.

7I. Mifflin RC, Saada JI, Di Mari JF, Valentich JD, Adegboyega PA, Powell DW: Aspirin-mediated COX-2 transcript stabilization via sustained p38 activation in human intestinal myofibroblasts. Mol Pharmacol 2004, 65:470-478.

72. Friis S, Poulsen AH, Sorensen HT, Tjonneland A, Overvad K, Vogel U, et al: Aspirin and other non-steroidal anti-inflammatory drugs and risk of colorectal cancer: A Danish cohort study. Cancer Causes Control 2009

\section{Pre-publication history}

The pre-publication history for this paper can be accessed here:

http://www.biomedcentral.com/1471-2407/9/407/pre

pub 